УДК 504.3.054:620.2-403.8

\title{
УРАН И ТОРИЙ В АЭРОЗОЛЬНЫХ ВЫПАДЕНИЯХ Г. НОВОСИБИРСКА И ЕГО ОКРЕСТНОСТЕЙ (ЗАПАДНАЯ СИБИРЬ)
}

\author{
Артамонова Светлана Юрьевна, \\ artam@igm.nsc.ru \\ Институт геологии и минералогии им. В.С. Соболева СО РАН, \\ Россия, 630090, г. Новосибирск, пр. Академика Коптюга, 3.
}

\begin{abstract}
Актуальность исследования обусловлена необходимостью развития геоэкологических подходов к оценке качества воздуха урбанизированных территорий и выявления вклада выбросов отдельных промышленных источников в общее техногенное загрязнение городского воздуха.

Цель: определить техногенную аэрозольную нагрузку и аэрозольное выпадение $T h$ и $U$ в окрестностях пяти крупных промышленных предприятий г. Новосибирска.

Объекты: пылеаэрозольные частицы, накопленные в снеговом покрове окрестностей ТЭЦ-2, ТЭЦ-3, ТЭЦ-5, Новосибирского оловокомбината и Новосибирского завода химических концентратов в течение зимнего периода. Техногенная радиоактивная составляющая в аэрозолях г. Новосибирска и его окрестностей ранее в открытой печати подробно не рассматривалась.

Методы: отбор крупнообъемных проб снегового покрова (до 400 дм³) для выделения путем фильтрования достаточной для анализов навески твердых взвесей из талого снега; определение плотности среднесуточного выпадения аэрозолей (среднесуточной аэрозольной нагрузки) путем расчетов через отношение массы твердых взвесей, полученных из проб талого снега, к площади отбора и количеству суток существования снегового покрова (со дня формирования снегового покрова до отбора пробы); определение содержания сажи в аэрозолях путем озоления при 550 C, определение содержания Th и U рентгенофрлуоресцентным методом на синхротронном излучении и масс-спектрометрическим методом на индуктивно-связанной плазме. Результаты. На основе данных плотности среднесуточного выпадения аэрозолей в пределах основных ореолов выбросов промышленных предприятий г. Новосибирска проведена оценка загрязнения воздуха городской среды. Определено содержание в аэрозолях Th и U и плотность их выпадения на поверхность земли вместе с аэрозолями. Наиболее высокое содержание урана установлено в аэрозолях, отобранных в пределах ореола выбросов Новосибирского завода химконцентратов. Выявлены особенности поступления Th и U с выбросами ТЭЦ при сжигании бурого и каменного углей.
\end{abstract}

\section{Ключевые слова:}

Промышленные выбросы, аэрозольные выпадения, техногенные аэрозоли, снеговой покров, радионуклиды, торий, уран, Новосибирск.

\section{Введение}

Загрязнение воздуха мегаполисов, промышленных центров является актуальной геоэкологической проблемой, которой занимается все больше исследователей и число публикаций по этой теме с каждым годом растет [1]. При поиске по ключевым словам «роwer station, emission, pollution» в корневой базе данных Web of Science на 19.12.2019 г. найдено 186 опубликованных работ. То, что большая половина из них представлена авторами из четырех стран: 33 - из Китая, 23 - из России, 23 - из США, 21 - из Индии, косвенно подтверждает, что проблема аэрозольного загрязнения приземного воздуха особо остро стоит в тех странах, где наблюдаются большие темпы промышленного роста, как Китай [2], и в странах, где доминирует угольная энергетика, как Россия [3], где 67,7 \% электроэнергии вырабатывается на ТЭЦ (на 01.01.2019 г.) [4]). Большое внимание придается изучению аэрозольных частиц меньше 10 и 2,5 мкм в силу их высокой биологической доступности и, следовательно, повышенных рисков для здоровья человека [5].

Радиоактивная составляющая аэрозольных выпадений в основном изучается с точки зрения оценки последствий ядерных испытаний XX в., аварий на Фукусиме и Чернобыльской АЭС: 14 из 21 найденных публикаций по ключевым словам «aerosol, fallout, uranium» посвящены именно этим проблемам радиоэкогеохимии искусственных радиоизотопов. Особый интерес вызывают объекты ядерно-топливного цикла (ЯТЦ), с выбросами которых в окружающую среду поступает обогащенный уран с пониженным ${ }^{238} \mathrm{U} /{ }^{235} \mathrm{U}$ отношением [6]. Глобальность масштабов техногенных выбросов в приземном слое атмосферы проявлялся в установлении в аэрозольных выпадениях Японии обедненного урана во время войны в Ираке 2003 г., по-видимому, вызванного использованием бронебойных снарядов с обедненным ураном [7], как и обогащенного урана в аэрозолях Арканзаса, как последствие аварийного падения летательного аппарата в Канаде в 1980 г. [8].

Между тем уран и торий - естественные радионуклиды - могут начать интенсивно переноситься в приземном слое атмосферы в результате сжигания больших объемов угля [5]. На примере крупных мегаполисов Китая выявлено, что в Китае уран и торий являются одними из основных компонентов мелкодисперсных техногенных аэрозолей урбанизированных территорий [2].

Аэрозоли, как правило, собирают путем прямого отбора проб на фильтрах или выделяют из дождевой воды [2, 9]. Формирование и сохранение снегового покрова в условиях Сибири, севера США и Канады дает возможность отбирать интегральные пробы 
аэрозолей, накопленных в снегу за зимний период [10-12]. Эти пробы дают возможность оценить аэрозольные выпадения в целом за сезон, выявить более общие закономерности на небольшом количестве проб, чем при прямом отборе проб. В составе аэрозолей, накопленных в снеге склона Скалистых гор, четко прослеживается региональное влияние частиц из соленых озер и почв штата Юта, переносимых ветром [11]. В Сибири первыми пробы снега изучали исследователи г. Новосибирска в рамках проекта «Аэрозоли Сибири»: было выявлено влияние эрозии солончаков и засоленных почв Казахстана в формировании состава аэрозолей Новосибирской области [13].

Большой задел в изучении снега окрестностей топливно-энергетических предприятий, где сжигается уголь, сделан исследователями Томского политехнического университета $[3,12,14,15]$. В снеге U, Lu, Zn, $\mathrm{F}, \mathrm{Cs}$, в почвах $\mathrm{Sr}, \mathrm{Eu}, \mathrm{Lu}$ были определены в качестве геохимических индикаторов выбросов Сибирского химического комбината [15], этот список индикаторных элементов далее был расширен за счет всего ряда P3Э, а также Th, Ba, Y, Nb, Zr, Tl, также в аэрозолях СХК впервые установлено снижение изотопного отношения ${ }^{238} \mathrm{U} /{ }^{235} \mathrm{U}$ до 74,28 [16].

Проблема техногенной радиоактивной составляющей в аэрозолях г. Новосибирска и его окрестностей в связи с выбросами предприятия атомной энергии - Новосибирского завода химических концентратов (НЗХК) - впервые обсуждалась в открытой печати [17]. С тех пор продолжается накопление фактических данных путем ежегодного отбора крупнообъемных проб снега и изотопно-геохимического изучения жидкой и твердой фазы снега.

Целью работы было определить в окрестностях крупных промышленных предприятий г. Новосибирска радиоактивную составляющую аэрозольной техногенной нагрузки путем установления плотности среднесуточного выпадения аэрозолей и содержания Th и $\mathrm{U}$ в аэрозолях.

\section{Краткая характеристика промышленных источников выбросов г. Новосибирска}

В настоящее время к наиболее крупным промышленным источникам выбросов г. Новосибирска можно отнести четыре теплоэнергетических предприятия (ТЭЦ-2, ТЭЦ-3, ТЭЦ-4 и ТЭЦ-5) и два комбината: Новосибирский Оловокомбинат (ОК) и Новосибирский завод химконцентратов (НЗХК) (рис 1). ТЭЦ-2 и ТЭЦ-3 с трубами высотой 100 и 120 м расположены на левом берегу р. Обь. ТЭЦ-4 с трубой всего в 60 м, являющаяся спутником НЗХК, и наиболее крупная ТЭЦ-5 с высокой трубой в 260 м расположены на правобережной части города. Мощность ТЭЦ-5 превосходит остальные ТЭЦ от 2,2 до 2,6 раз [18] (рис. 2) На всех ТЭЦ г. Новосибирска в качестве основного топлива используется уголь: бурые угли Назаровского, Бородинского разрезов Канско-Ачинского угольного бассейна - на ТЭЦ-3 и с 2018 г. - на ТЭЦ-5, а каменные угли Кузнецкого угольного бассейна - на остальных ТЭЦ (в т. ч. на ТЭЦ-5 до 2018 г.). Известно, что бурые угли при гипергенном окислении и под действием грунтовых вод нередко накапливали уран [19]. Каменные угли Кузнецкого угольного бассейна часто отличаются высокой зольностью и значимым содержанием $\mathrm{U}$ и $\mathrm{Th}$, обусловленных содержанием в углях кластического вулканогенного материала [19]. Следовательно, есть основания ожидать наличие $U$ и Th в выбросах ТЭЦ г. Новосибирска.

Ранее проведенными исследованиями было выявлено, что ОК - предприятие цветной металлургии, расположенное на левобережье г. Новосибирска, является источником значительного загрязнения городского воздуха мышьяком, оловом и комплексом халькофильных металлов [10], но до настоящего времени содержание урана, тория в его выбросах еще не оценивалось

Предприятие ядерно-топливного цикла НЗХК со спутником - ТЭЦ-4, расположено на северовосточной окраине города. На НЗХК выпускаются топливные элементы для атомных станций и исследовательских реакторов на протяжении более 30 лет. Производство связано с ураном [20], потому возможное поступление урана с выбросами НЗХК в городской воздух нуждается в изучении.

Таким образом, актуальность оценки аэрозольных выпадений урана и тория в окрестностях перечисленных промышленных предприятий не подлежит сомнению, поскольку это касается экологического благополучия городской среды.

\section{Экспериментальная часть}

В Новосибирске в зимнее время преобладают ветры южного и юго-западного направлений [21], поэтому пробоотбор снегового покрова проводился по маршруту с подветренной стороны от труб предприятий в середине месяца март, за исключением 2015 г., когда он был проведен на месяц раньше - в середине февраля.

Вокруг труб ОК, ТЭЦ-2 и ТЭЦ-3 отбор проб проводился на расстояние до 3 км до берега р. Обь (рис. 1). На правобережье из-за отсутствия участков с ненарушенным снеговым покровом отбор снега проведен только на берегу р. Обь.

Обширная промзона НЗХК не позволяет отбор проб с подветренной стороны ближе чем в 4 км. Труба ТЭЦ-5 превышает в 2,2-4,5 раза трубы других ТЭЦ и эффективно рассеивает ее выбросы на большей территории. В результате маршруты проботбора в пределах основных ореолов этих предприятий были более протяженными - до 10 км (рис. 1). Кроме того, аэрозольные выпадения изучались на юго-восточной части г. Новосибирск: около Новосибирского Академгородка (АГ), около пос. Ключи (Кл). Участки АГ и Кл отличаются удаленностью от шлейфов выбросов рассматриваемых крупных промышленных источников. Для исключения влияния автодорог пробоотбор проводился на удалении в 200 м и более от дорог. Фоновый участок выбран с наветренной стороны в 12 км к юго-западу от города (рис. 1).

Снеговой покров отбирался на всю его мощность, в каждой точке проходили от нескольких до десятка шурфов (рис. 3), объем пробы составлял от 70 до 
200 дм $^{3}$, а в фоновой точке - 400 дм³ $^{3}$ Крупнообъемные пробы снега позволили получить навески твердых аэрозолей, достаточные для проведения всего комплекса лабораторных анализов. Пробы снега растаивали в закрытых пластиковых емкостях. Твердую взвесь отделяли путем фильтрования с использованием бумажного фильтра «синяя лента».
Плотность среднесуточного выпадения аэрозолей (мг $/ \mathrm{M}^{2} \cdot$ сут), так называемая аэрозольная нагрузка, определялась как отношение массы взвесей к площади отбора и периоду существования устойчивого снежного покрова до отбора пробы. Содержание сажистых частиц в аэрозолях определялось путем озоления при $550{ }^{\circ} \mathrm{C}$.

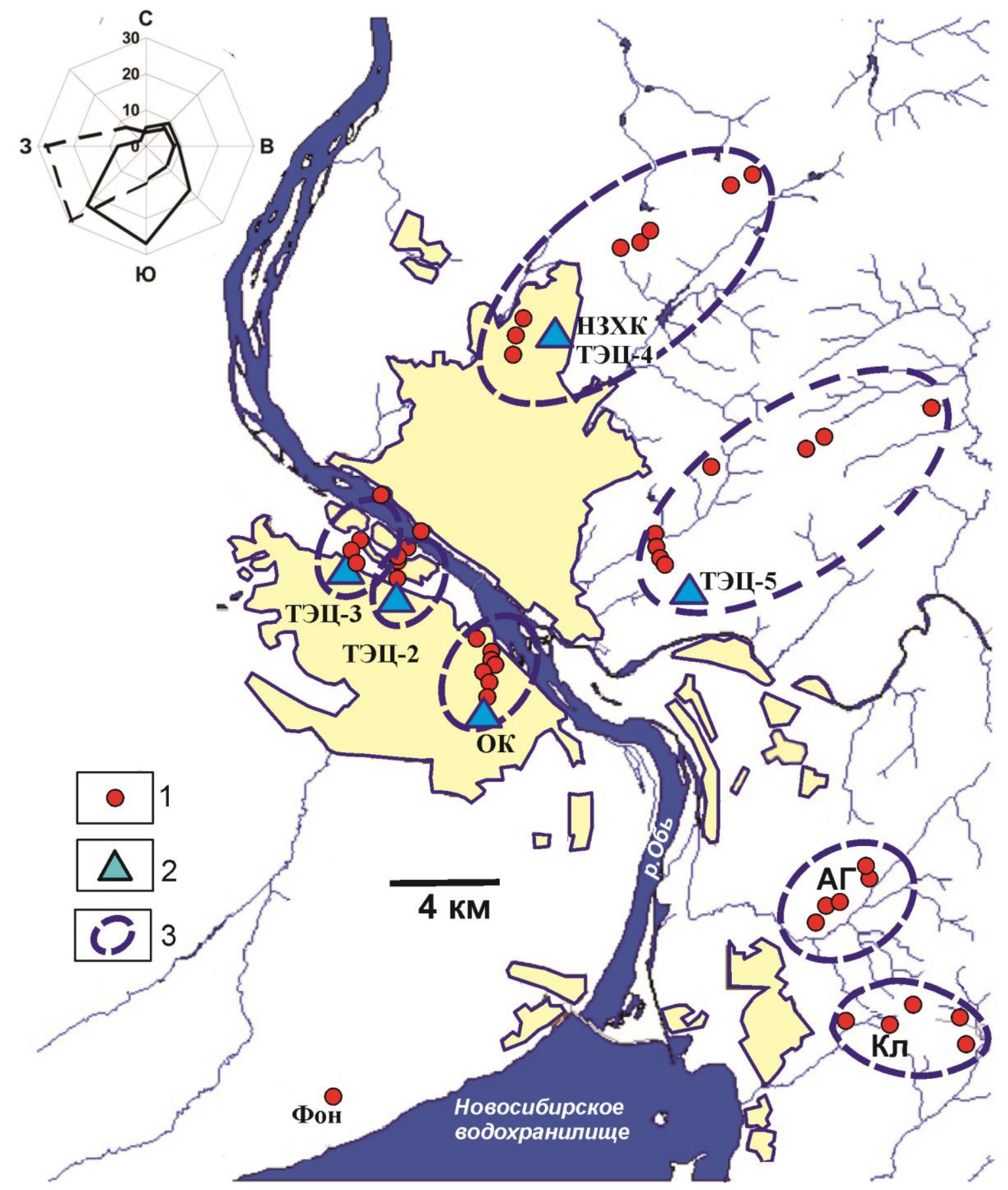

Pис. 1. Расположение промышленных предприятий г. Новосибирска и точек отбора проб снежного покрова. Условные обозначения: 1 - точки отбора проб снега; 2 - предприятия - крупные источники выбросов; 3 - ореоль техногенного аэрозольного загрязнения. Сокращения названий предприятий см. по тексту. Наверху слева роза ветров в зимнее время [21] (сплошная линия - в приземном воздухе, прерывистая линия - на высоте 500 м)

Fig. 1. Position of the plants in Novosibirsk city and sampling points. Legend: 1 - snow sampling points; 2 - the plants significant sources of industrial emission; 3 -aureoles of aerosol pollution. Acronyms of the plants see in the text. The wind rose diagram [21] is shown on the left up (line - on the earth surface, dash line - on the $500 \mathrm{~m}$ of high) 


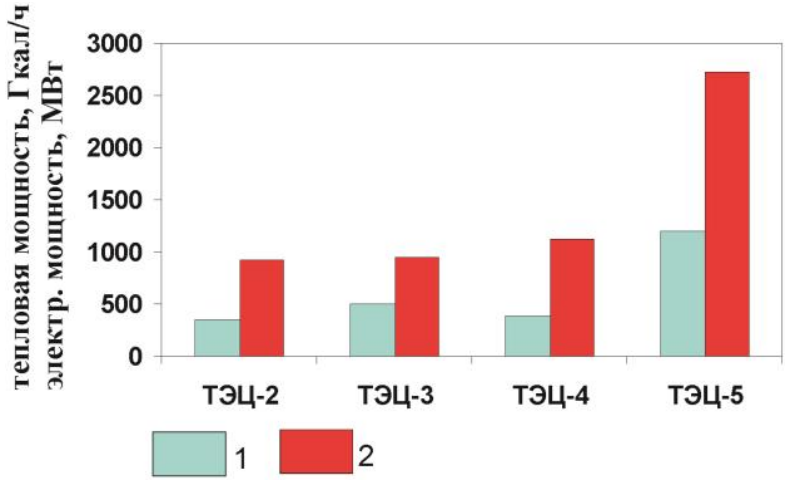

Содержание U, Th и других элементов определено на ЦКП «Сибирский центр синхротронного и террагерцового излучения» ИЯФ СО РАН рентгенофлуоресцентным методом на синхротронном излучении (РФА-СИ) с нижним пределом обнаружения до 0,3 г/т с относительной погрешностью $\leq 15 \%$, использовался внешний стандарт почвы SOIL-7 MAГАТЭ. Большим преимуществом метода является простая подготовка - гомогенизация и таблетирование 30 мг
Рис. 2. Электрическая (МВт) (1) и тепловая (Гкал/ч) (2) мошность ТЭЦ г. Новосибирска [18]

Fig. 2. Electrical $(M W)(1)$ and heat-generating (GCal/h) (2) power of Heat-Electricity generating plants of Novosibirsk city [18] сухой навески с сохранением в пробе летучих и легких компонентов. Метод позволяет получить количественные данные о содержании 35 элементов, включая $\mathrm{U}$ и $\mathrm{Th}$ [22]. Дополнительно привлекался массспектрометрический метод на индуктивно-связанной плазме (МС-ИСП) на масс-спектрометр ELEMENT (Finnigan Mat, Germany), для анализов навеска в 100 мг предварительно озолялась и переводилась в раствор.
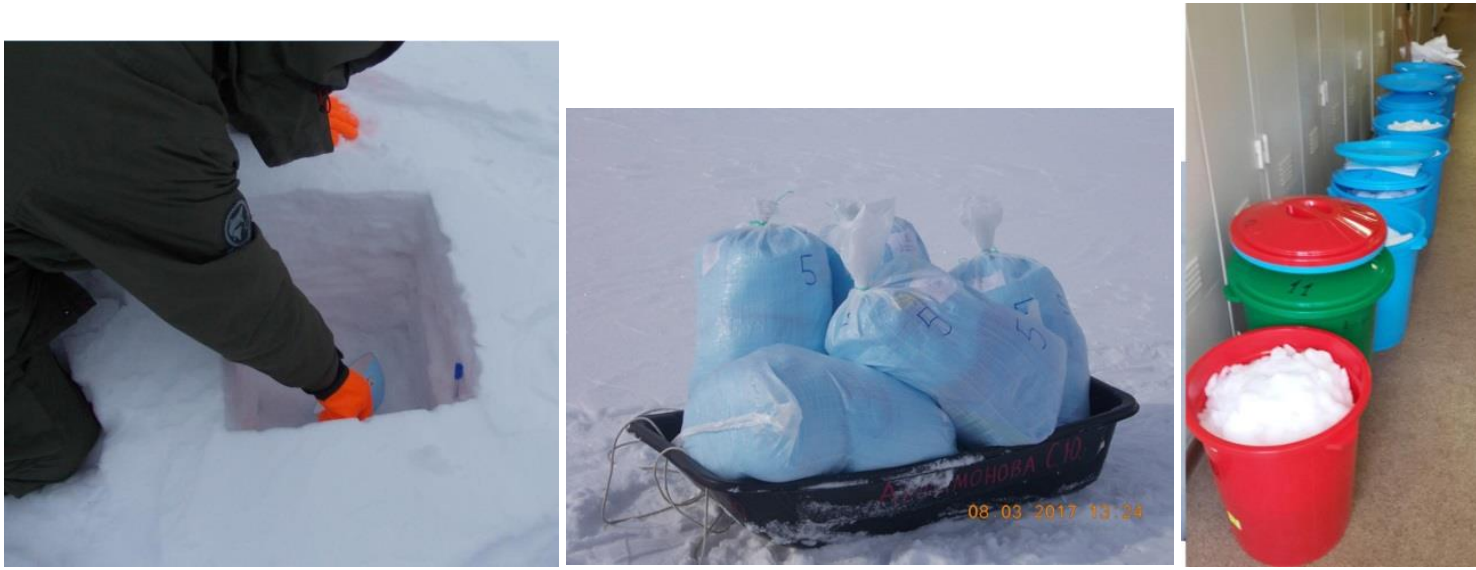

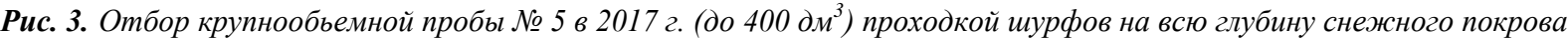
и один из этапов ее подготовки

Fig. 3. Hand pit in snow cover sampling of large volume (until $400 \mathrm{dm}^{3}$ in volume) of the snow sample No. 5 in 2017 and one of the steps of sampling preparation

\section{Результаты и обсуждение}

Чем загрязненнее воздух, тем больше аэрозолей связывается при снегопаде со снегом и выпадает, аккумулируясь в снеговом покрове. Следовательно, плотность выпадения аэрозолей адекватно отражает степень загрязненности местного городского воздуха. Наиболее высокая средняя плотность среднесуточного выпадения аэрозолей за 2011, 2014-2017 гг. оказалась присуща ореолу ТЭЦ-3 - 137 мг/м² ·ут (рис. 4).

На ТЭЦ-3 сжигается бурый уголь. По-видимому, из-за большего содержания летучих компонентов и влаги в буром угле по сравнению с каменным углем и более низкой температуры его горения образуется больше выбросов и, соответственно, наблюдается высокая аэрозольная нагрузка в ореоле ТЭЦ-3. В ореоле расположенного поблизости ТЭЦ-2, где сжигается каменный уголь, средняя плотность среднесуточного выпадения аэрозолей меньше $-107 \mathrm{M \Gamma} / \mathrm{M}^{2} \cdot$ сут.
Плотность среднесуточного выпадения аэрозолей в разные годы остается примерно одинаковым, что указывает на постоянство доминирующих источников выбросов на местности в зимний период. Например, в ореоле НЗХК, имеющего единый ореол выбросов со спутником ТЭЦ-4, плотность среднесуточного выпадения аэрозолей в разные годы составляла от 97 до $102 \mathrm{M \Gamma} / \mathrm{M}^{2} \cdot$ сут, только в 2015 г. - всего 60,4 мг·сут $/ \mathrm{M}^{2}$. По-видимому, на снижение показателя в 2015 г. повлиял более ранний отбор пробы - в феврале вместо марта, т. е. сокращение примерно на 1 месяц периода позиционирования снегового покрова в качестве депонирующего слоя (рис. 5).

В ореоле самой мощной, примерно в 2,5 раза превышающей мощности других, ТЭЦ-5 (рис. 2), где на время отбора проб (до 2018 г.) основным топливом был каменный уголь, плотность среднесуточного выпадения аэрозолей оказалась невысокой и составила 
67 мг/м² зольной нагрузке в ореоле ТЭЦ-5, по-видимому, способствует более эффективное рассеивание выбросов с высоты 260-метровой трубы. Возможно, также это результат более эффективного золоулавливания, ведь ТЭЦ-5 наиболее современная по сравнению с остальными городскими ТЭЦ (год ввода ТЭЦ-5 - 1985 г. [18]). В пределах ореола ОК средняя плотность среднесуточного выпадения аэрозолей составила $67 \mathrm{Mг} / \mathrm{M}^{2} \cdot$ сут, как и в ореоле ТЭЦ-5.

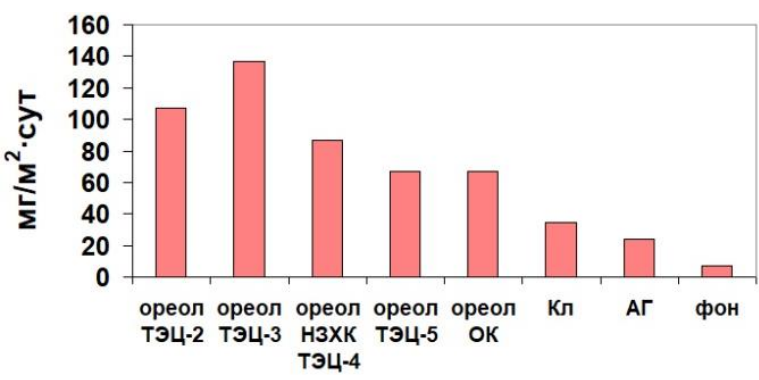

Puc. 4. Средняя за 2011, 2014-2017 г2. плотность среднесуточного выпадения аэрозолей в ореолах промышленных предприятий 2. Новосибирска

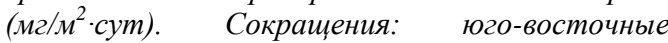
окрестности 2. Новосибирска: Кл - участок Ключи, АГ - около Новосибирского Академгородка. Фон - фоновый участок в 12 км к югозападу от города (район пос. Плановый)

Fig. 4. Mean diurnal aerosol fallout in oreols of the plants $\left(\mathrm{mg} / \mathrm{m}^{2} \cdot\right.$ day) in 2011, 2014-2017. Legend: $\mathrm{Kr}$ - site Klyuchi, AT-site Akademgorodok on the easternsouth vicinity of the Novosibirsk, Фон - background site in $12 \mathrm{~km}$ toward southern-west from Novosibirsk (vicinity of settlement Planovuy)

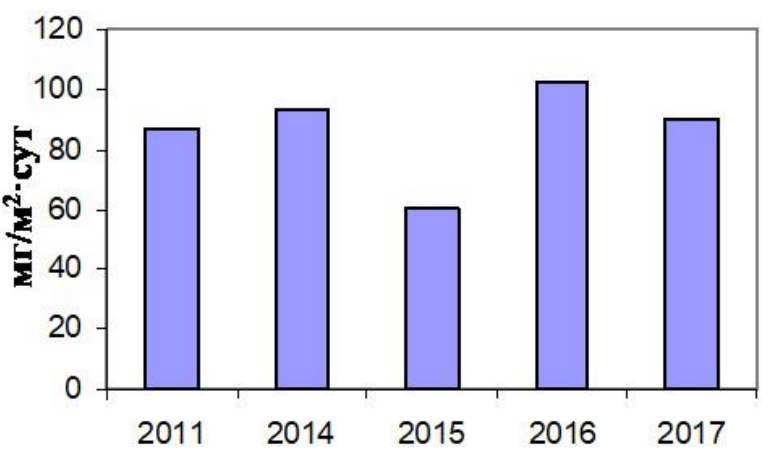

Рис. 5. Средняя плотность среднесуточного выпадения аэрозолей в ореоле НЗХК (со спутником ТЭЦ-4) зимой $\left(\right.$ мг/м $\left.\mathrm{M}^{2} \cdot \mathrm{cym}\right)$ по даннылм снеговых проб в 2011-2017 г2.

Fig. 5. Mean diurnal aerosol fallout in oreols of the NCCP (with satellite HEPP-4) $\left(\mathrm{mg} / \mathrm{m}^{2} \cdot\right.$ day) by the data of snow samples in 2011-2017

Вдали от крупных промышленных предприятий, в юго-восточной окрестности г. Новосибирска, вблизи Новосибирского Академгородка, обозначенного как участок АГ (рис. 1), среднесуточная аэрозольная

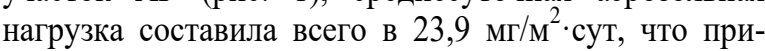
мерно в 3 и более раза меньше, чем в ореолах промышленных предприятий города, и, следовательно, на столько же здесь чище воздух. Аэрозольная нагрузка на участке Кл - 34,3 мг/ $\mathrm{M}^{2} \cdot$ сут, что примерно в 2 раза ниже нагрузки промышленных районов, но выше, чем на участке АГ (рис. 1, 4). Предполагается, что участок Кл подвергается загрязнению выбросов г. Бердска, расположенного к юго-востоку от него. Фоновый участок отличается от всех других изученных участков самой низкой среднесуточной аэрозольной нагрузкой - в среднем всего 7,2 мг/ $\mathrm{M}^{2} \cdot$ сут (рис. 4).

Выявлено гетерогенное распределение содержания $\mathrm{U}$ и Th в аэрозолях, что позволило на Th-U диаграмме оконтурить шесть геохимических полей (рис. 6).

Геохимическое поле № 1 на левом нижнем углу Th-U диаграммы сформировано аэрозолями участка АГ - среднее содержание Th составило 5,4 г/т, U 1,6 г/т.

Аэрозоли в ореоле схожих по мощности ТЭЦ-2 и ТЭЦ-3 отличаются по содержанию радионуклидов: на U-Th диаграмме они формируют геохимические поля № 2 и 3 . В аэрозолях ТЭЦ-3 содержание и взаимное отношение Th и U варьируют в широком диапазоне, в связи с этим оконтурено геохимическое поле № 2 сложной конфигурации. Среднее содержание радионуклидов низкое: $\mathrm{Th}-5,3$ г/т, U - 2,5 г/т. Геохимическое поле № 3 - компактное. В аэрозолях ТЭЦ-2 среднее содержание Th составляет 10,1 г/т, a U 3,0 г/т.

Аэрозоли участка Ключи на диаграмме Th-U большей частью попадают в геохимическое поле № 3, среднее содержание Th составляет 9,3 г/T, a U - 3,5 г/т. Аэрозоли Оловокомбината (ОК) формируют компактное геохимическое поле № 4 в центральной части Th-U диаграммы со средним содержанием $\mathrm{Th}-7,0$ г/ и $U-3,4$ г/т.

Аэрозоли ТЭЦ-5 и НЗХК (совместно с ТЭЦ-4) формируют геохимические поля № 5 и 6 в правой части Th-U диаграммы. Главным образом аэрозоли НЗХК и ТЭЦ-5 отличаются от аэрозолей других участков тем, что содержат больше U. Среднее содержание U в аэрозолях ореола НЗХК - 5 г/т, в аэрозолях ТЭЦ-5 - 4,7 г/т, а среднее содержание Тh 12,3 и 10,5 г/т соответственно. Наиболее высокое содержание U в 9,9 г/т обнаружено в 4,8 км к северо-востоку от НЗХК.

Итак, геохимическое поле № 1 сформировано аэрозолями участка АГ. Это вполне логично - здесь, вдали от крупных промышленных предприятий, характерны не только слабая аэрозольная нагрузка (рис. 4), но и низкое содержание радионуклидов в аэрозолях - среднее содержание $\mathrm{Th}-5,74$ и $\mathrm{U}-1,6$ г/т, что даже немного ниже фонового содержания. Среднее содержание Th на фоновом участке составило 7,0 г/т, $\mathrm{U}-2,43$ г/т, что близко к кларковым содержаниям в почвах - 7,8 и 2 г/т [23]. По Л.П. Рихванову в природных геосистемах распространены, как правило, Th/U отношения в диапазоне от 2,5 до 5,0 [24]. Среднее $\mathrm{Th} / \mathrm{U}$ отношение в фоновых аэрозолях составило 2,86 , что лежит в диапазоне обычных природных отношений. По-видимому, на фоновом участке преобладают аэрозоли природного происхождения. Поскольку 
аэрозольная нагрузка на АГ в 3 раза превышает фоновый уровень (рис. 4), техногенный привнос аэрозолей, по-видимому, с малым содержанием радионуклидов, приводит к разубоживанию содержания Th и $\mathrm{U}$ в аэрозолях. Среднее $\mathrm{Th} / \mathrm{U}$ отношение в аэрозолях АГ равно 3,2 - в пределах природного диапазона (рис. 7,8$)$. В связи с этим можно предположить, что на участке АГ доминируют выбросы локального источника с низким содержанием Th и U c сохранением их природного соотношения (возможно, например, пыление при сельскохозяйственном или строительном производстве).

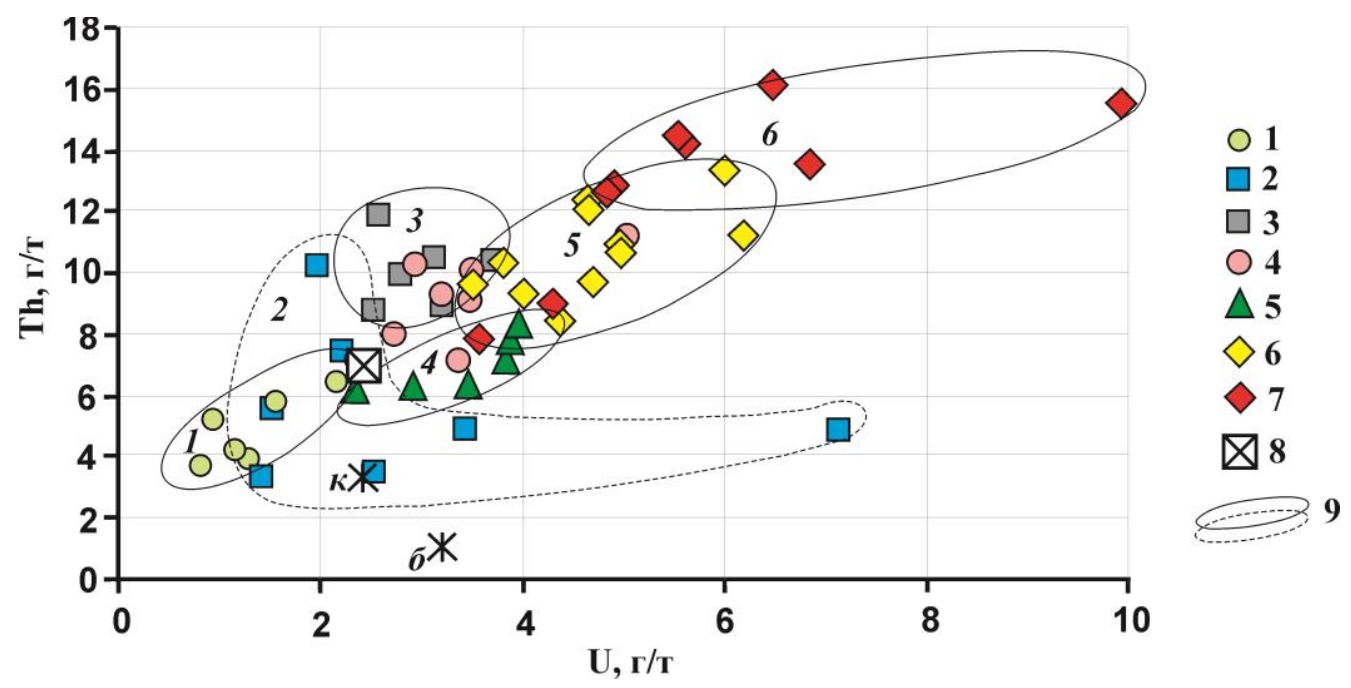

Pис. 6. Содержание Th и U в аэрозолях Новосибирска и его окрестностей, г/m. Условные обозначения: аэрозоли: 1 участка АГ (юго-восточной окрестности г. Новосибирска около Академгородка вне основных ореолов крупных промышленных предприятий), аэрозоли из ореолов выбросов: 2 - ТЭЦ-3; 3 - ТЭЦ-2; 4 - участка Ключи (Кл), 5 - Оловокомбината (ОК), 6-ТЭЦ-5, 7 - НЗХК и ТЭЦ-4; 8 - фоновый участок; 9 - среднее содержание Th и U в каменных углях Кузбасса (к) и бурых углях Канско-Ачинского бассейна (б) по С.И. Арбузову [19]); 10 - геохимические поля: 1 - вне основных ореолов крупных промышленных предприятий; 2 - ореол ТЭЦ-3; 3 - ореол ТЭЦ-2; 4 - Оловокомбинат (ОК); 5 - ореол ТЭЦ-5; 6 - ореол НЗХК и ТЭЦ-4

Fig. 6. Th and U content in aerosol of Novosibirsk city and its vicinity, g/t. Designations: aerosol samples from the aureoles of: 1 - south-east of Novosibirsk vicinity outside the aureoles of major emissions from industrial enterprises (AG); 2 - HEPP-3; 3 - HEPP-2; 4 - Klyuchi site (Kl); 5 - NTP (OK); 6 - HEPP-5; 7 - NCCP and HEPP-4; 8 background site, 9 - average Th and $U$ content in coal from the Kuznetsky Basin ( $k$ ) and Kansk-Achinsk Basin (b) according to S.I. Arbuzov [19]; 10 - Geochemical fields: 1 - outside major aureoles of aerosol pollution; 2 aureoles of pollution from HEPP-3, 3 -aureoles of pollution from HEPP-2; 4 -aureole of pollution from NTP $(O K)$; 5 - aureoles of pollution from HEPP-5, 6 - aureole of pollution from NTTP and HEPP-4

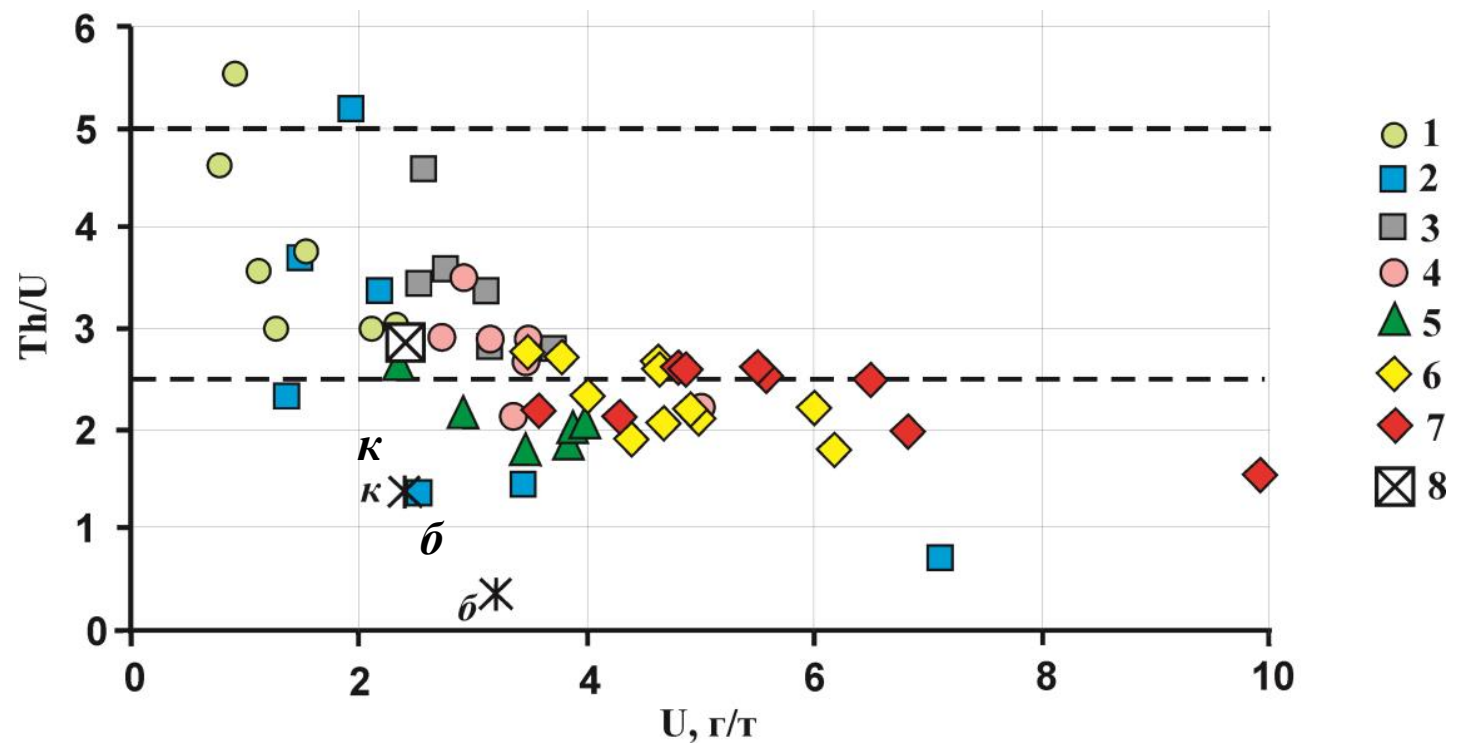

Pис. 7. Отношение Th/U в аэрозолях Новосибирска и его окрестностей. Условные обозначения см. на рис. 6. Прерывистой линией показан диапазон Th/U значений от 2,5 до 5 для природных систем

Fig. 7. Th/U ratio in the aerosols of Novosibirsk city and its vicinity. Legend see in Fig. 6 . The range of values Th/U $(2,5-5)$ of natural geosystems is shown by cut-lines 


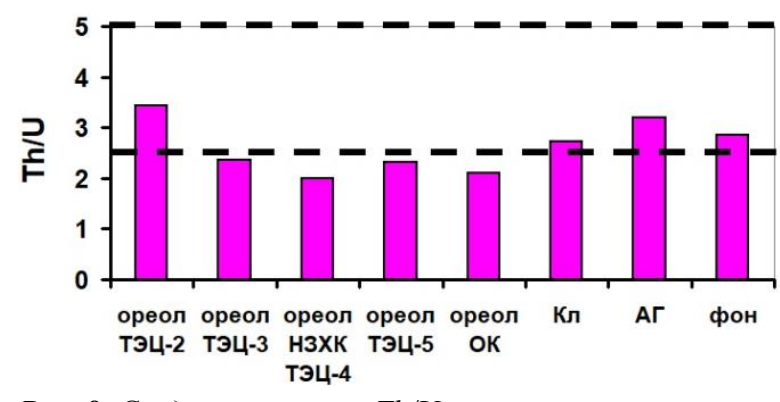

Pис. 8. Среднее значение Th/U отношения в аэрозолях Новосибирска и его окрестностей. Сокращцения см. На рис. 4. Прерывистой линией показан диапазон Th/U значений от 2,5 до 5 для природных систем

Fig. 8. Mean $T h / U$ ratio in the aerosol of Novosibirsk city and its vicinity. Acronyms see in Fig. 4. The range of values $T h / U(2,5-5)$ of natural geosystems is shown by cut-lines

В аэрозолях ореола ТЭЦ-2 содержание Тh в 2 раза больше, чем в аэрозолях ТЭЦ-3, а содержание U больше всего на $20 \%$. Известно, что среднее содержание тория в каменных углях Кузнецкого угольного бассейна равно 3,3 г/т, что примерно в 3 раза превышает его среднее содержание в бурых углях Канско-Ачинского бассейна, равное 1 г/т [19]. В каменных углях Кузнецкого угольного бассейна зольность в основном формируется за счет содержащегося в них пеплового вулканогенного материала с сосредоточенными в них Th, U и редкоземельными элементами [19]. В углях уран еще содержится в рассеянной форме в органической части углей, особенно в бурых углях, подвергшихся гипергенным преобразованиям: при взаимодействии с грунтовыми водами бурые угли могут значительно сорбировать из воды уран и др. элементы [19]. Таким образом, различие в содержании $\mathrm{U}$, Th в аэрозолях ТЭЦ-2 и ТЭЦ-3, весьма схожих по техническим параметрам и с одинаковым геоэкологическим расположением, повидимому, обусловлено различием в составе их топлива - каменных углей Кузнецкого угольного бассейна на ТЭЦ-2 и бурых углей Канско-Ачинского угольного бассейна на ТЭЦ-3. Можем говорить о том, что исходная радиоактивная составляющая углей предопределяет состав выбросов ТЭЦ-2 и ТЭЦ-3.

В аэрозолях г. Новосибирска выявлена сильная обратная корреляционная зависимость содержания Th от содержания сажи с коэффициентом $-0,74$ (рис. 9) или, наоборот, положительная корреляционная зависимость от зольной части с коэффициентом 0,74 в отличие от $\mathrm{U}$, коэффициент корреляции которого и сажи составил всего $-0,48$. Сильная связь содержания Th от зольного (минерального) вещества аэрозолей свидетельствует о переносе основной доли Тh с минеральными (пепловыми) частицами, а не с частицами сажи. Как правило, минеральные аэрозольные частицы крупнее и плотнее сажистых частиц и они выпадают раньше $[10,17]$, и вместе с ними выпадает, по-видимому, и основная доля $\mathrm{Th}-$ на более близком расстоянии от трубы, чем U. Уран, не проявляющий ясной корреляционной связи, как торий, по-видимому, в аэрозолях присутствует как в составе преимуще- ственно зольных (пепловых) частиц, так и в дисперсном виде в составе частиц сажи, способных переноситься по воздуху на дальние расстояния.

Возьмем, к примеру, аэрозоли участка Ключи: они по содержанию Th и U похожи на аэрозоли ТЭЦ-2, попадают в его геохимическое поле № 3 на Th-U диаграмме (рис. 6).

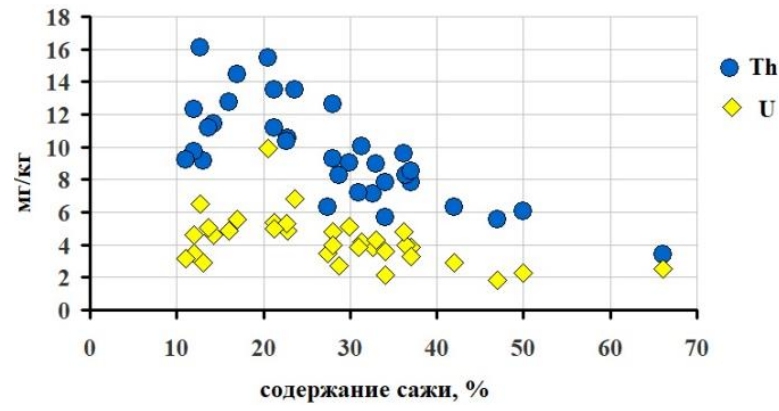

Pис. 9. Обратная корреляционная связь содержания Th $(2 / m)$ и сажи (масс. \%) в аэрозолях г. Новосибирска

Fig. 9. Negative correlation between the content of Th (ppm) and organic furnace black (mass. \%) in aerosol of the vicinity of the Novosibirsk city

Это указывает на схожесть источника аэрозольного загрязнения участка Ключи с ТЭЦ-2. Предполагается, что на участок Ключи влияют также выбросы от сжигания каменного угля в местных котельных, или долетают выбросы из г. Бердска, расположенного в 10 км к юго-западу. Заметим, что среднее содержание Тh в аэрозолях участка Ключи чуть меньше, чем в аэрозолях ТЭЦ-2, зато в них чуть больше содержание U. Это как раз можно объяснить большей удаленностью от предположительного источника выбросов в г. Бердске - примерно на 10 км, и, следовательно, более глубоким фракционированием аэрозолей по крупности в процессе переноса аэрозолей, чем это происходит в пределах 3-километрого ореола ТЭЦ-2. При этом выпадает большая доля Th, связанная с крупными пепловыми частицами, по сравнению с $\mathrm{U}$, имеющем двойственную природу. Заметим, что среднесуточная аэрозольная нагрузка на участке Ключи примерно в 3 раза ниже, чем в ореоле ТЭЦ-2, что соответствует разнице расстояний от источников выбросов.

Как видно на рис. 6,7 , среднее $\mathrm{Th} / \mathrm{U}$ отношение в аэрозолях ТЭЦ-2 равно 3,43 и располагается в диапазоне обычных значений для геосистем. Как и ожидалось, к нему близко среднее отношение $\mathrm{Th} / \mathrm{U}$ в аэрозолях участка Ключи, оно равно 2,73, что попадает также в диапазон природных значений.

В аэрозолях ТЭЦ-3 среднее отношение $\mathrm{Th} / \mathrm{U}$ существенно ниже - всего 2,36, что, по-видимому, обусловлено исходно низким содержанием Тh и относительно высоким содержанием U в бурых углях Канско-Ачинского бассейна.

А каково $\mathrm{Th} / \mathrm{U}$ отношение в аэрозолях ТЭЦ-5, где, как и на ТЭЦ-2, до 2018 г. сжигался каменный уголь? Отметим, что среднее содержание Th в аэрозолях ТЭЦ-5 примерно такое же, как в аэрозолях ТЭЦ-2: 10,5 и 10,1 г/т соответственно. При этом $\mathrm{Th} / \mathrm{U}$ в аэро- 
золях ТЭЦ-5 всего 2,31, тогда как в аэрозолях ТЭЦ-2 оно равно 3,43 и располагается в диапазоне природных значений. Именно более высокое содержание U в аэрозолях ТЭЦ-5 привело к уменьшению $\mathrm{Th} / \mathrm{U}$ отношения. Вопрос «откуда в аэрозолях ТЭЦ-5 так много урана?» пока остается открытым. Выбросы ТЭЦ-2 и ТЭЦ-5, получаемые из одного и того же каменного угля, в аэрозолях формируют близкие содержания тория. Трудно представить, что в процессе золоулавливания на ТЭЦ-5 происходит обогащение выбросов ураном. На сегодня можно только допустить, что высокое содержание U в аэрозолях ореола ТЭЦ-5 появилось за счет выбросов НЗХК. Ввиду близости НЗХК, одинаковых геоэкологических условий размещения на возвышенности Сокур, их выбросы по мере перемещения главным образом на северо-восток, согласно доминирующим направлениям ветра, могут смешиваться и накладываться. Следовательно, картина аэрозольного загрязнения в ореолах НЗХК и ТЭЦ5 может быть более сложной.

В аэрозолях ТЭЦ-3 среднее отношение $\mathrm{Th} / \mathrm{U}$ coставляет всего 2,36, что, по-видимому, обусловлено исходно низким содержанием Th и относительно высоким содержанием U в бурых углях КанскоАчинского бассейна. Известно, что As, Sn являются основными индикаторами выбросов ОК [10]. Но среднее отношение $\mathrm{Th} / \mathrm{U}$ в аэрозолях ОК составляет 2,11 , что указывает на то, что U скорее всего также является второстепенным компонентом выбросов ОК.

Наиболее низкие значения $\mathrm{Th} / \mathrm{U}$ отношения характерны аэрозолям ореола НЗХК (и спутника ТЭЦ-4): в среднем оно равно 2,0 (рис. 8). ТЭЦ-4 похож на ТЭЦ-2 как по техническим параметрам (рис. 2), так и по виду топлива на обоих предприятиях сжигается каменный уголь, поэтому вклад выбросов ТЭЦ-4 в аэрозолях сформировал бы примерно такое же содержание U, как и в аэрозолях ТЭЦ-2 - около 3 г/т. Следовательно, при среднем содержании урана в 5 г/т, остальные 2 г/т, или $40 \%$, урана в аэрозолях, по-видимому, являются вкладом выбросов собственно НЗХК. Здесь в аэрозолях содержание Тh на $22 \%$ больше, чем в аэрозолях ТЭЦ-2, и на $17 \%$ больше, чем в аэрозолях ТЭЦ-5: 12,7 г/Т против 10,07 г/Т и 10,52 г/Т соответственно. Поскольку производство НЗХК связано с ураном, маловероятно, чтобы источником Th являлись собственно выбросы НЗХК, скорее всего, их основным источником являются выбросы сжигания угля на ТЭЦ-4. По-видимому, низкая труба высотой всего в 60 м способствует более интенсивному и плотному выпадению пепловых частиц с Th в окрестностях предприятия. Для достоверного определения основных источников $\mathrm{Th}$ в аэрозолях ореола НЗХК (вместе со спутником ТЭЦ-4) необходимо дальнейшее изучение.

В аэрозолях выявлена умеренная обратная корреляционная зависимость $\mathrm{Th} / \mathrm{U}$ отношения от содержания U c коэффициентом -0,65 (рис. 7). Следовательно, именно вариации содержания $\mathrm{U}$, нежели $\mathrm{Th}$, определяют Th/U отношение в аэрозолях г. Новосибирска. В свою очередь, на основании этого можно говорить о существенно более высокой миграционной способности урана в техногенном аэрозольном переносе по сравнению с торием.
На основе плотности среднесуточного выпадения аэрозолей и среднего содержания радионуклидов в аэрозолях оценена плотность выпадения Th и U на каждом изученном участке г. Новосибирска и его окрестностей (г/га·год) (рис. 10). Оказалось, что наиболее сильное выпадение тория присуще ореолам ТЭЦ с низкими трубами, где основным топливом является каменный уголь: в ореоле ТЭЦ-4 (спутника НЗХК) и ТЭЦ-2 - 3,91 и 3,93 г/га·год соответственно. Данные выпадений в ореоле ТЭЦ-4 (НЗХК), вероятно, получились ниже, чем было бы при схеме отбора, как в ореоле ТЭЦ-2, поскольку вблизи от трубы с подветренной стороны отсутствует возможность отбора пробы. В ореоле ТЭЦ-5, благодаря высокой трубе и эффективному рассеиванию выбросов, и, возможно, лучшему золоулавливанию плотность аэрозольного поступления Тh в 1,5 раза ниже, чем на ТЭЦ-2 и ТЭЦ-4, и составляет 2,6 г/га.год. В ореоле ТЭЦ-3 аэрозольное выпадение в целом высокое, потому плотность выпадения Тh получилось умеренным - 2,8 г/га·год, несмотря на его малое содержание в аэрозолях, количество выпадающего урана - 1,25 г/га·год - это больше, чем в ореоле ТЭЦ-2 и ТЭЦ-5.

Больше всего выпадает U в ореоле НЗХК (со спутником ТЭЦ-4) - 1,6 г/га·год. В ореолах ТЭЦ-2 и ТЭЦ-5 выпадает примерно одинаковое количество урана: 1,17 и 1,14 г/га·год. Если допустить, что от выбросов ТЭЦ-4 поступает столько же урана, как и на ТЭЦ-2 1,15 г/га·год, значит, разницу в 0,45 г/га·год следует принять за «вклад» именно атомного производства.

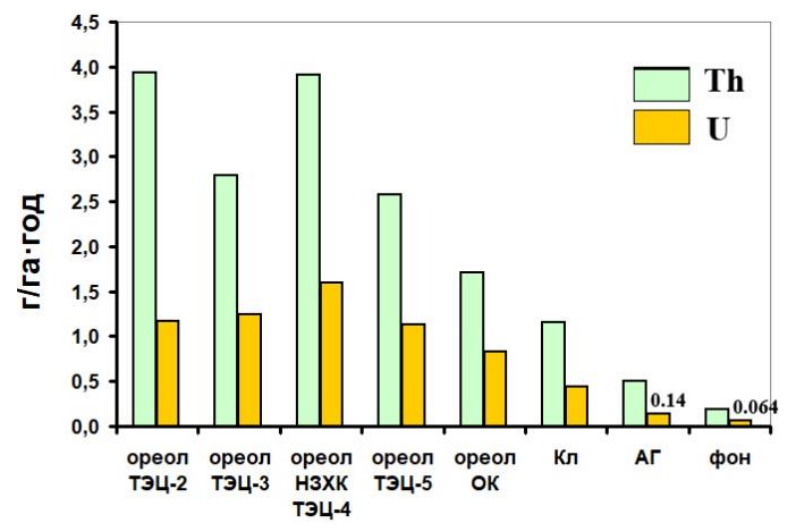

Рис. 10. Аэрозольное поступление Th (1) и U (2) (г/2а год) в г. Новосибирске и его окрестностях. Сокращенные наименования ореолов предприятий $u$ участков см. на рис. 4

Fig. 10. Aerosol pollution by Th (1) and U (2) (gram on the hectare per year) in Novosibirsk city and its vicinity. Acronyms see in Fig. 4

По сравнению с ореолами других промышленных предприятий ореол ОК загрязняется радионуклидами меньше: Th - 1,7 и U - 0,83 г/га·год, что в принципе логично - радионуклиды не являются основными составляющими полиметаллических руд, перерабатываемых на комбинате.

На участке Кл при всей схожести состава аэрозолей с аэрозолями ТЭЦ-2 поступление Тh всего - 
1,16 г/га·год и U - 0,43 г/га·год вследствие меньшей аэрозольной нагрузки. На участке АГ аэрозольное загрязнение Th и U еще ниже: 0,5 и 0,14 г/га·год соответственно. На фоновом участке наблюдается самое слабое аэрозольное поступление радионуклидов: Th $0,18, \mathrm{U}-0,06$ г/га·год, что в 21 и 25 раз ниже, чем в ореоле НЗХК.

\section{Выводы}

1. В пределах основных ореолов выбросов шести крупных промышленных предприятий г. Новосибирска оценена аэрозольная нагрузка: наиболее сильная наблюдается в ореоле выбросов ТЭЦ-3, где средняя плотность среднесуточного выпадения аэрозолей в 2011 г. и 2014-2017 гг. составила $137 \mathrm{M \Gamma} / \mathrm{m}^{2} \cdot$ сут, в ореолах выбросов остальных источников - от 67 до $107 \mathrm{мг} / \mathrm{M}^{2} \cdot$ сут. Вне основных шлейфов промышленных выбросов аэрозольная нагрузка в 2-3 раза меньше: на участке около Академгородка и на участке Ключи средняя плотность среднесуточного выпадения аэрозо-

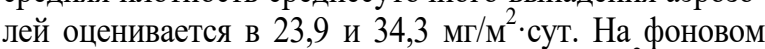
участке аэрозольная нагрузка всего $7,2 \mathrm{Mг} / \mathrm{M}^{2} \cdot$ сут, что на порядок ниже аэрозольной нагрузки в ореолах крупных промышленных предприятий.

2. Выявлено гетерогенное распределение Th, U в аэрозолях г. Новосибирска. Главными источниками $\mathrm{Th}, \mathrm{U}$ в аэрозолях являются выбросы ТЭЦ, где сжигается каменный уголь. Выбросы НЗХК являются значительным источником $\mathrm{U}$ в аэрозолях.

Больше всего радионуклидов в аэрозолях окрестностей НЗХК (со спутником ТЭЦ-4), где среднее содержание U составило 5,0 г/T, Th $-12,3$ г/т. Здесь наблюдается наибольшая плотность выпадения U 1,6 г/га·год. Примерно 40 \% урана в аэрозолях или примерно 0,45 г/га·год, выпадающего на поверхность земли урана, поступает, по самой предварительной оценке, с выбросами собственно производства НЗХК. Остальная часть урана, по-видимому, формируется в основном за счет выбросов сжигания угля на ТЭЦ-4. На остальных изученных участках плотность выпадения U значительно меньше: от 0,14 до 1,25 г/га·год.

Больше всего Тh выпадает в ореоле невысоких труб ТЭЦ, где сжигается каменный уголь: в ореолах выбросов ТЭЦ-2 и ТЭЦ-4 (спутника НЗХК) плотность выпадения Тh составляет примерно 3,9 г/га·год соответственно. На остальных изученных участках выпадает значительно меньше Th: от 0,5 до 2,8 г/га·год.

В ореоле ОК аэрозольное загрязнение U и Th caмое слабое среди ореолов крупных промышленных предприятий города: Th - 1,7 и U - 0,83 г/га·год. Это соответствует его производственной специфике радионуклиды не являются основными составляющими полиметаллических руд, перерабатываемых на комбинате, и здесь отсутствует сжигание угля в больших объемах, как на ТЭЦ.

Среди рассмотренных участков, подвергающихся техногенному аэрозольному загрязнению, наиболее чистый участок на юго-восточной окрестности города - на участке Аг, где выпадает почти в 10 раз меньше Th и U по сравнению с аэрозольным загрязнением в ореоле НЗХК, что составляет 0,5 и 0,14 г/га.год соответственно.

В аэрозолях фонового участка содержание Th coставило 7,0 г/т, U - 2,43 г/т, что близко к кларку почв и указывает на преимущественно природное происхождение аэрозолей (из частиц почв, грунтов). На фоновом участке воздух наиболее чистый: аэрозольное поступление $\mathrm{Th}$ и $\mathrm{U}$ в 21 и 25 раз меньше аэрозольного выпадения радионуклидов в ореоле НЗХК и составляет всего 0,18 и 0,064 г/га·год соответственно.

3. На примере ТЭЦ-2 и ТЭЦ-3 с похожими техническими параметрами при одинаковом геоэкологическом расположении выявлено различие в аэрозольном загрязнении при сжигании каменного (на ТЭЦ-2) и бурого (на ТЭЦ-3) углей. При сжигании бурого угля Канско-Ачинского угольного бассейна образуется примерно на 30 \% больше выбросов, чем при сжигании каменного угля Кузнецкого угольного бассейна. В силу содержания Th, U в пепловом вулканогенном компоненте каменных углей, в выбросах сжигания каменных углей значительно больше Th, чем в выбросах сжигания бурых углей. В аэрозолях ореола ТЭЦ-2 содержание Тh в 2 раза, U на $20 \%$ больше, чем в аэрозолях ореола ТЭЦ-3. С учетом аэрозольной нагрузки в ореоле ТЭЦ-2 выпадает примерно на 40 \% больше Тh, чем в ореоле ТЭЦ-3, при примерно одинаковой плотности выпадения U. По схожести содержания Th и $\mathrm{U}$ в аэрозолях участка Ключи с аэрозолями ореола ТЭЦ-2 сделан вывод об аэрозольном загрязнении участка Ключи выбросами сжигания каменных углей, предположительно, переносящихся по розе ветров со стороны г. Бердска, расположенного в 10 км к юго-востоку от участка.

4. В аэрозолях г. Новосибирска выявлена высокая обратная корреляционная зависимость содержания Th от содержания сажи с коэффициентом корреляции 0,74, что указывает на связь Тh именно с минеральной (зольной) частью аэрозолей. Вместе с тем $U$ в аэрозолях содержится как в минеральной зольной части, так и в сажистых частицах, то есть его формы нахождения в аэрозолях более разнообразны.

5. Аэрозолям г. Новосибирска и его окрестностей характерны низкие значения $\mathrm{Th} / \mathrm{U}$ отношения, часто близкие к 2,5 - нижней границе природного диапазона значений, что, по-видимому, отражает более высокую миграционную способность урана в техногенных системах промышленных выбросов по сравнению с торием. Умеренная отрицательная корреляционная зависимость $\mathrm{Th} / \mathrm{U}$ от содержания U с коэффициентом корреляции $-0,65$ указывает на то, что отношение $\mathrm{Th} / \mathrm{U}$ в аэрозолях определяется главным образом ураном, нежели более пассивным торием.

Аналитические работы проведены в ЦКП «Сибирский иентр синхротронного и терагериового излучения» ИЯФ СО РАН и ЦКП многоэлементных и изотопных исследований СО РАН. Работа выполнена по государственному заданию ИГМ СО РАН и при поддержке грантов РФФИ № 14-05-00289, № 18-45-140020. 


\section{СПИСОК ЛИТЕРАТУРЫ}

1. Chak K.Ch., Xiaohong Y. Air pollution in mega cities in China // Atmospheric environment. - 2008. - V. 42. - P. 1-42.

2. Monitoring of ultra-trace uranium and thorium in six-grade particles / X. Shao, Y. Xu, Y. Zhang, L. Yin, X. Kong, Y. Ji // Chemosphere. - 2019. - V. 233. - P. 76-80.

3. Dmitrienko M.A., Strizhak P.A. Coal-water slurries containing petrochemicals to solve problems of air pollution by coal thermal power stations and boiler plants: an introductory review // Science of the total environment. - 2018. - V. 613. - P. 1117-1129.

4. Интернет-сайт Министерства энергетики Российской Федерации. URL: https://minenergo.gov.ru/node/532 (дата обращения 02.12.2019).

5. Russell M.C., Belle J.H., Liu Y. The impact of three recent coalfired power plant closings on Pittsburgh air quality: a natural experiment // Journal of the Air \& Waste Management Association. - 2017. - V. 67. - № 1. - P. 3-16.

6. Bellis D.J., Ma R., McLeod C.W. Characterisation of airborne uranium and thorium contamination in northern England through measurement of $\mathrm{U}$, Th and $235 \mathrm{U} / 238 \mathrm{U}$ in tree bark // Journal of Environmental Monitoring. - 2001. - № 3 (2) . - P. 198-201.

7. Transport of carbon-bearing dusts from Iraq to Japan during Iraq's war / K. Tazaki, R. Wakimoto, Y. Minami et al. // Atmospheric Environment. - 2004. - V. 38. - Iss. 14. - P. 2091-2109.

8. Sakuragi Y., Meason J.L., Kuroda P.K. Uranium and plutonium isotopes in the atmosphere // Journal of Geophysical Research: Oceans. - 1983. - V. 88. - Iss. C6. - P. 3718-3724.

9. Characterization of total suspended particles around a power station in an urban coastal area in eastern Spain / A. Boix, M.M. Jordan, X. Querol, T. Sanfeliu // Environmental geology. - 2001. V. 40. - P. 891-896.

10. Артамонова С.Ю., Попов Н.А. Элементный состав твердых осадков снежного покрова в районе Новосибирского оловокомбината (2005-2016 гг.) // ИНТЕРЭКСПО ГЕО-СИБИРЬ. - 2017. - Т. 4. № 2. - C. 141-145. URL: https://elibrary.ru/item.asp?id=29197824 (дата обращения 12.12.2019)

11. Composition of dust deposited to snow cover in the Wasatch Range (Utah, USA): controls on radiative properties of snow cover and comparison to some dust-source sediments / R.L. Reynolds, H.L. Goldstein, B.M. Moskowitz, A.C. Bryant, S.M. Skiles, R.F. Kokaly, C.B. Flagg, K. Yauk, T. Berquo, G. Breit, M. Ketterer, D. Fernandez, M.E. Miller, T.H. Painter // Aeolian research. - 2014. - V. 15. - P. 73-90.

12. Characterization of solid airborne particles deposited in snow in the vicinity of urban fossil fuel thermal power plant (Western Siberia) / A.V. Talovskaya, E.G. Yazikov, E.A. Filimonenko, J.-C. Lata, J. Kim, T.S. Shakhova // Environmental Technology. V. 39. - № 18. - P. 2288-2303.
13. Особенности формирования ионного состава атмосферных аэрозолей и осадков на юге Западной Сибири / Б.С. Смоляков, Л.А. Павлюк, К.П. Куценогий, П.К. Куценогий, В.И. Макаров, И.Ю. Конченко // Химия в интересах устойчивого развития. 1997. - T. 5. - № 2. - С. 193-200.

14. Экологические риски от влияния токсичных элементов в атмосферном воздухе на основе изучения снежного покрова в районе расположения Томской ГРЭС-2 / Н.А. Осипова, А.В. Таловская, Е.А. Филимоненко, Е.Г. Язиков, С.А. Новиков // Известия Томского политехнического университета. Инжиниринг георесурсов. - 2018. - Т. 329. - № 4. - С. 54-69. URL: http://earchive.tpu.ru/bitstream/11683/47212/1/bulletin_tpu-2018v329-i4-06.pdf (дата обращения 12.12.2019).

15. Язиков Е.Г., Таловская А.В. Радиоэкологическая оценка территории на основе изучения атмосферных пылевых выпадений методом осколочной радиографии // Известия высших ученых заведений. Геология и разведка. - 2013. - № 5. C. 57-61. URL: https://elibrary.ru/item.asp?id=20879956 (дата обращения 12.12.2019).

16. Артамонова С.Ю. Геохимические особенности аэрозольного загрязнения в районе Сибирского химического комбината // Химия в интересах устойчивого развития. - 2012. - Т. 20. № 4. - C. 405-418. URL: https://elibrary.ru/item.asp?id=17978502 (дата обращения 12.12.2019).

17. Артамонова С.Ю. Уран в техногенных аэрозолях промышленных районов Новосибирска // Химия в интересах устойчивого развития. - 2012. - Т. 20. - № 5. - С. 507-513. URL: https://elibrary.ru/item.asp?id=18226765(дата обращения 12.12.2019).

18. Интернет сайт Сибирской энергетической компании. URL: https://sibgenco.ru (дата обращения 02.12.2019).

19. Формы нахождения урана в углях и торфах Северной Азии / С.И. Арбузов, С.С. Ильенок, А.В. Волостнов, С.Г. Маслов, В.С. Архипов // Известия Томского политехнического университета. - 2011. - Т. 319. - № 1. - С. 109-115.

20. Интернет сайт Новосибирского завода химконцентратов. URL: http://www.nccp.ru/ (дата обращения 02.12.2019).

21. Интернет сайт ФГБУ «Западно-Сибирское УГMC». URL: http://meteo-nso.ru/pages/46 (дата обращения 02.12.2019).

22. Станция РФА-СИ на накопительном кольце ВЭПП-4М / А.А. Легкодымов, К.Э. Купер, Ю.П. Колмогоров, Г.Н. Баранов // Известия Российской академии наук. Серия физическая. - 2019. - Т. 83. - № 2. - С. 158-162.

23. Иванов В.В. Экологическая геохимия элементов. Кн. 6. Редкие f-элементы. - М.: Экология, 1997. - 607 с.

24. Рихванов Л.П. Радиоактивные элементы в окружающей среде и проблемы радиоэкологии. - Томск: STT, 2009. - 430 с.

Поступила 16.06.2020 2.

\section{Информация об авторах}

Артамонова С.Ю., доктор геолого-минералогических наук, старший научный сотрудник Института геологии и минералогии им. В.С. Соболева СО РАН. 
UDC 504.3.054:620.2-403.8

\title{
URANIUM AND THORIUM IN AEROSOL FALLOUT OF NOVOSIBIRSK CITY AND ITS VICINITY (WEST SIBERIA)
}

\author{
Svetlana Yu. Artamonova, \\ artam@igm.nsc.ru
}

V.S. Sobolev Institute of Geology and Mineralogy SB RAS,

3, Academician Koptyug avenue, Novosibirsk, 630090, Russia.

The relevance of the study is caused by the necessity to develop geoecological approaches to evaluation of air quality in the urban territories and to determine the contribution of the emissions of separate industrial sources into the technogenous pollution of urban air. The aim of the study is to determine the technogenous aerosol load and aerosol-based precipitation of Th and $U$ in the vicinity of five large industrial enterprises of Novosibirsk.

Objects: dust and aerosol particles accumulated in the snow cover in the vicinity of Heat Stations No. 2, 3, 5, Novosibirsk Tin Plant and Novosibirsk Plant of Chemical Concentrates during the winter season. The technogenous component in the aerosol of Novosibirsk and its vicinities was not previously considered in detail in open publications.

Methods: large-volume (up to $400 \mathrm{dm}^{3}$ ) sampling of snow cover to isolate the portions of suspensions from melted snow by filtering, so that the amount of solid suspensions would be sufficient for analyses; determination of the density of diurnal aerosol precipitation (diurnal aerosol load) through calculations of the ratio of the mass of solid suspensions from the samples of melted snow to the sampling area and the number of days during which the snow cover exists (since the day when the snow cover was formed till the sampling date); determination of soot content in aerosol by ashing at $550{ }^{\circ} \mathrm{C}$, determination of Th and $U$ content by means of $X$-ray fluorescence with the synchrotron radiation.

Results. On the basis of the density of diurnal aerosol precipitation within the major aureoles of emissions from industrial enterprises of Novosibirsk, evaluation of the pollution of urban air is carried out. The content of Th and $U$ in aerosol and the density of their precipitation on the Earth's surface with aerosol are determined. The highest uranium content was established in aerosol samples collected within the aureole of emissions from the Novosibirsk Plant of Chemical Concentrates. The features of Th and $U$ arrival with the emissions from heat stations during the combustion of brown and black coal are determined.

\section{Key words:}

Industrial emission, aerosol fallout, technogenic aerosol, snow cover, radionuclides, thorium, uranium, Novosibirsk.

The analysis was carried out in the Core Facility Centre «Siberian Center of Synchronous and Teraherz Radiation»INP SB RAS and the Core Facility Centre of multielement and isotopic research of SB RAS. The research was carried out by the state task of IGM SB RAS and supported by the RFBR grants no. 14-05-00289, 18-45-140020.

\section{REFERENCES}

1. Chak K.Ch., Xiaohong Y. Air pollition in mega cities in China Atmospheric environment, 2008, vol. 42, pp. 1-42.

2. Shao X., Xu Y., Zhang Y., Yin L., Kong X., Ji Y. Monitoring of ultra-trace uranium and thorium in six-grade particles. Chemosphere, 2019, vol. 233, pp. 76-80.

3. Dmitrienko M.A., Strizhak P.A. Coal -water slurries containing petrochemicals to solve problems of air pollution by coal thermal power stations and boiler plants: An introductory review. Science of the total environment, 2018, vol. 613, pp. 1117-1129.

4. Internet-sait Ministerstva Energetiki Rossiyskoy Federatsii [The WEB site of the Ministry of Energy of Russian Federation. Available at: https://minenergo.gov.ru/node/532 (accessed 2 December 2019).

5. Russell M.C., Belle J.H, Liu Y. The impact of three recent coalfired power plant closings on Pittsburgh air quality: a natural experiment. Journal of the Air \& Waste Management Association, 2017, vol. 67, no. 1, pp. 3-16.

6. Bellis D.J., Ma R., McLeod C.W. Characterisation of airborne uranium and thorium contamination in northern England through measurement of $\mathrm{U}$, Th and $235 \mathrm{U} / 238 \mathrm{U}$ in tree bark. Journal of Environmental Monitoring, 2001, no. 3 (2), pp. 198-201.

7. Tazaki K., Wakimoto R., Minami Y. Transport of carbon -bearing dusts from Iraq to Japan during Iraq`s war. Atmospheric Environment, 2004, vol. 38, Iss. 14, pp. 2091-2109.

8. Sakuragi Y., Meason J.L., Kuroda P.K. Uranium and plutonium isotopes in the atmosphere. Journal of Geophysical Research: Oceans, 1983, vol. 88, Iss. C6, pp. 3718-3724.

9. Boix A., Jordan M.M., Querol X., Sanfeliu T. Characterization of total suspended particles around a power station in an urban coastal area in eastern Spain. Environmental geology, 2001, vol. 40, pp. 891-896.
10. Artamonova S.Yu., Popov N.A. Element composition of fallout, accumulated in snow blanket of Novosibirsk tin plant area] INTEREXPO GEO-Siberia, 2017, vol. 4, no. 2, pp. 141-145. In Rus. Available at: https://elibrary.ru/item.asp?id=29197824 (accessed 12 December 2019).

11. Reynolds R.L., Goldstein H.L., Moskowitz B.M., Bryant A.C., Skiles S.M., Kokaly R.F., Flagg C.B., Yauk K., Berquo T., Breit G., Ketterer M., Fernandez D., Miller M.E., Painter T.H. Composition of dust deposited to snow cover in the Wasatch Range (Utah, USA): Controls on radiative propertities of snow cover and comparison to some dust-source sediments. Aeolian research, 2014, vol. 15, pp. 73-90.

12. Talovskaya A.V., Yazikov E.G., Filimonenko E.A., Lata J.-C., Kim J., Shakhova T.S. Characterization of solid airborne particles deposited in snow in the vicinity of urban fossil fuel thermal power plant (Western Siberia). Environmental Technology, vol. 39, no. 18, pp. 2288-2303.

13. Smolyakov B.S., Pavlyuk L.A., Koutsenogiy K.P., Koutsenogiy P.K., Makarov V.I., Konchenko I.Yu. Special aspects of ion composition of atmospheric aerosols in the South of the West Siberia. Chemistry for Sustainable Development, 1997, vol. 5, pp. 193-200. In Rus.

14. Osipova N.A., Talovskaya A.V., Filimonenko E.A., Yazikov E.G., Novikov S.A. Ecological risks caused by toxic elements impact on ambient air determined in the study of the snow cover in Tomsk GRES-2 area. Bulletin of the Tomsk Polytechnic University. Geo Assets Engineering, 2018, vol. 329, no. 4, pp. 54-69. In Rus. Available at: http://earchive.tpu.ru/bitstream/11683/47212/1/ bulletin_tpu-2018-v329-i4-06.pdf (accessed 12 December 2019).

15. Yazikov E.G., Talovskaya A.V. Radioecological estimation of a region on the basis of studying insoluble fraction in the aerosols in 
snow by the method of fission - fragment radiography. Izvestiva Vysshikh Uchenykh Zavedeniy. Geologiya i Razvedka, 2013, no. 5, pp. 57-61. In Rus. Available at: https://elibrary.ru/item.asp?id=20879956 (accessed 12 December 2019)

16. Artamonova S.Yu. Geochemical features of aerosol pollution in the region of the Siberian Chemical Combine. Chemistry for Sustainable Development, 2012, vol. 20, pp. 361-374. Available at: http://sibran.ru/upload/iblock/0e4/0e409405495ef753cf9f84a7944 ela4c.pdf

17. Artamonova S.Yu. Uranium in technogenic aerosol of the industrial areas of Novosibirsk. Chemistry for Sustainable Development, 2012, vol. 20, pp. 457-463. Available at: http://sibran.ru/upload/iblock/c1a/c1a7227f31d069042c305f92ff76 230a.pdf (accessed 12 December 2019).

18. Internet sayt Sibirskoy energeticheskoy kompanii [WEB site of the Siberian Generating Company]. Available at: https://sibgenco.ru (accessed 2 December 2019).

19. Arbuzov S.I., Ilenok S.S., Volostnov A.V., Maslov S.G., Arhipov V.S. Modes of occurrence of Uranium and Thorium in coals and peats of Northern Asia. Bulletin of the Tomsk Polytechnic University, 2011, vol. 319, no. 1, pp. 109-115. In Rus.
20. Internet sayt Novosibirskogo zavoda khimkontsentratov [WEB site of the Novosibirsk Chemical Concentrates Plant]. Available at: http://www.nccp.ru/ (accessed 2 December 2019).

21. Internet sayt «Zapadno-Sibirskoe UGMS»] [WEB site of the Federal State Budgetary Institution «West Siberian Department hydrometeorology and Environmental Monitoring»]. Available at: http://meteo-nso.ru/pages/46 (accessed 2 December 2019).

22. Legkodymov A.A., Kuper K.E., Kolmogorov Yu.P., Baranov G.N The SRXFA Station on the VEPP-4M Storage Ring. Bulletin of the Russian Academy of Sciences: Physics, 2019, vol. 83, no. 2, pp. 112-115. In Rus.

23. Ivanov V.V. Ekologicheskaya geokhimiya elementov. Kn. 6. Redkiie f-elementy [Ecological Geochemistry of elements. B. 6. Rare f-elements]. Moscow, Ekologiya Publ., 1997. 607 p.

24. Rikhvanov L.P. Radioaktivnye elementy v okruzhayushchey srede $i$ problemy radioekologii [Radioactive elements in environment and problems of radioecology]. Tomsk, STT Publ., 2009. 430 p.

Received: 16 June 2020.

\section{Information about the authors}

Svetlana Yu. Artamonova, Dr. Sc., senior researcher, V.S. Sobolev Institute of Geology and Mineralogy SB RAS. 